\title{
MathE - Improve Mathematical Skills in Higher Education
}

\author{
Maria F. Pacheco \\ Center for Research \& \\ Development in Mathematics and \\ Applications (CIDMA) \\ Instituto Politécnico de Bragança \\ Bragança, Portugal \\ pacheco@ipb.pt
}

\author{
Ana Pereira \\ Centre in Digitalization and \\ Intelligent Robotics (CeDRI) \\ Instituto Politécnico de Bragança \\ Bragança, Portugal \\ apereira@ipb.pt
}

\author{
Florbela Fernandes \\ Centre in Digitalization and \\ Intelligent Robotics (CeDRI) \\ Instituto Politécnico de Bragança \\ Bragança, Portugal \\ fflor@ipb.pt
}

\begin{abstract}
Higher education students of scientific subjects often lack the basic mathematical skills to follow lectures and make the most of the lecturer's teachings. It is necessary to identify the gaps in each students' understanding of the concepts and offer teachers adequate resources to motivate and provide their students the skills and competences they miss. The main goal of MathE - Improve Maths Skills in Higher Education is to encourage training and exchange in order to enhance and strengthen the quality of teaching and to support the use of digital and online technologies to improve pedagogies and assessment methods. MathE also aims to set up transnational teacher training courses and strengthen cooperation between universities that already offer such courses.
\end{abstract}

Keywords-higher education; pedagogical innovation; digital resources; open learning; distance learning; school development

\section{INTRODUCTION}

The variety of technological resources available for educational purposes is already quite large and it is constantly increasing ([13]) and scientific experiments and studies consistently confirm the usefulness of such resources (see [10] and [11]). Nevertheless, there is still a lack of formal qualification in digital skills within faculty training ([2], [7]). Up to now, many higher education institutions throughout Europe have established learning management systems, but such systems are implemented in an elementary way (such as uploading PDF files) rather than implementing blendedlearning scenarios ([4]).
At the same time, higher education institutions all over Europe are expected to take into account innovative technologies and scenarios such as Open Educational Resources (OER) or Massive Open Online Courses (MOOCs) ([1], [3], [5], [6], [7], [8], [12]).

The aim of the MathE project is to develop proficiency in teaching mathematics in higher education; MathE will engage teachers and their students, as well as external participants who want to deepen their knowledge of mathematics, in joint experiments involving the contents of the mathematics related courses in their institutions. The students can be challenged with materials such as videos, lessons, exercises, training tests and other formats, that will be freely available in the MathE library, an online database of teaching/learning resources. Teachers and students, together, can debate/discuss specific topics included in the online library, and they can also make contributions (with videos, exercises, ...) that will be validated by the teacher, prior to their inclusion in the MathE library. The intention is that the students can learn and practice maths outside and inside the classroom, with or without the presence of the teacher but, above all, whenever they wish to do and at their individual pace, relying on the tools provided by the MathE library.

\section{CONTRIBUtion OF MATHE}

The MathE project will make a significant contribution to innovation, developing, implementing and testing the effectiveness of new approaches to the learning of mathematical concepts. The use of the resources produced within the project will promote creativity as well as the introduction of unconventional practices in the scientific area of mathematics, traditionally taught in a very orthodox way: it usually relies on classroom lectures (by the teachers) and exercises solving (by the students). MathE ensures that education and research are mutually reinforcing by producing an online guidebook about the best practices in maths education. Such guide will promote interchange of learning 
experiences between maths teachers and researchers, as well as an increment in internationalization, mobility and cooperation of teachers of different institutions and backgrounds.

From the student's perspective, MathE will promote an increase in engagement, enthusiasm and sense of being challenged, since appealing digital educational resources that can be used as work tools, individually or as team work.

From the teacher's perspective, the MathE project will also stimulate the sense of challenge and motivation while encouraging the use of digital educational tools in the classroom. Resources for the evaluation of the students' progresses, that can be used as assessment for the mathematical contents of engineering/business courses, will be developed as well as a database of questions for selfevaluation and assessment.

Discussion among teachers and researchers about good practices in maths teaching will also be encouraged.

The MathE library, self-assessment, assessment and community of practice will be available freely at website mathe.pixel-online.org, and the project have the financial support of European Commission. Until now the project has forty university lectures and fifty university students, from five different countries: Portugal, Italy, Lithuania, Romania and Ireland. Other lectures and students can participate freely.

\section{Relation to Previous Projects}

Digital competence involves the confident and critical use of information society technology and, therefore, basic skills in information and communication technology (ICT). The project found inspiration in the Digital Agenda for Europe (DAE) and its basic underlying principle: helping Europe's citizens and businesses to get the most out of digital technologies.

Several previous European projects have contributed to improve the quality of teaching when educators rely on ICT based methodologies. The basic principle that is transversal to all is to enhance the lecturers' skills, knowledge and values towards the use of technology. This is why the MathE project makes use of the results of the following projects as examples:

E-learning From Nature: The E-Learning From Nature project proposed innovative teaching methodologies to science teachers, enhancing a proactive approach from the students towards the learning of scientific subjects. The students were invited to learn science through nature, relying on a collection of resources (information sheets, photos, videos and drawings available in digital format, as well as elessons) about the flora, the fauna, the natural elements and any other human intervention of scientific interest of a specific environmental area. The connection between the natural elements with school scientific curricular activities and the related basic skills to be acquired was a concern at every step.
INTACT - Interactive Teaching Materials Across Culture and Technology: the INTACT project addressed the school's growing need to attune to the fast development of the digital world. During the project, reliable teaching materials were developed for mathematics, natural and social sciences, to be used on such platforms as whiteboards, tablets and smartphones in order to promote a culture of collaboration among students and an interactive approach to learning.

These projects have included successful models and practices on how to train lecturers, and on the kind of workshops that are most useful for their needs, in order for them to embrace new ICT-skills and pedagogical models which can effectively be taken to the lecturer's practice. It is obvious that technologies for themselves are not sufficient to create successful learning environments; but in different levels of interaction, can motivate all educational agents and support in different learning scenarios, as describe in the education literature (see [9], [14] and [15]).

MathE - Improve Math Skills in Higher Education project concentrates on the promotion of the acquisition of mathematical skills using ICT tools for students, lecturers and other target groups. The need to encourage lecturers in the use of learning technologies in an advanced way and to increase digital media literacy is proven. The innovation that MathE presents is the offer, as output, of structured access to a variety of TEL-methods and TEL-resources in such a way that teachers can effectively find different TEL models, solutions, pedagogical theories and best practice in their classroom. The development of an e-resource kit, where scientific concepts are integrated and validated by lecturers and researchers, will represent a considerable step in the effectiveness of mathematics teaching and learning.

These innovative resources will be suitable and freely available for partner institutions and also accessible to other universities and educational organizations.

\section{IMPACT}

The main target groups are students, lecturers and researchers from higher education institutions.

Lecturers and researchers will improve their skills and refresh their practice when using the MathE library inside and outside the classroom. This will increase the diversity of their teaching approaches and adapt them to contemporary learning scenarios according to the students' needs.

Access and use of operational reference materials, such as guidelines and sample cases, will help to motivate the students to learn mathematics and to develop a more aware and autonomous mastery of the acquired knowledge.

The acquisition of new skills, the development of didactic methods through ICT tools and the group argumentation activities that will be implemented will contribute to motivate the students to learn mathematics through alternative pathways.

The impact envisaged on the students is very similar: since attending classes and studying will become more appealing, 
their skills, knowledge and attitude towards the use of technology enhanced materials will improve. The project will also strengthen the competence to be active in the use of ICT tools in different situations in the higher education process, taking into account each student's pace. Each student can learn by him/herself, test their knowledge autonomously and

be active in the whole process. Therefore, MathE project will provide digital support to overcome the mathematical gaps of each student.

For the higher-education institutions, the most important impact is getting access to a collection of tools, freely available online, which can be used by the students in order to improve their knowledge and, in the end, relate in a more consistent way to all other subjects that require a strong background in mathematics.

Another significant expected impact will be tackled through the creation and establishment of a community of practice, which will be able to share and spread each member's best teaching practices through their participation in training workshops or even through their involvement in the conception and implementation of the database of resources. A solid network of stable relationships and teaching exchanges will be created and it is expected that its joint activities will continue to exist after the end of MathE project. Several multiplier events will be organized to disseminate the results reached, the methodology implemented and output produced in the MathE project. The participants in the multiplier events will be higher education lecturers and students.

By the end of the project the expected results of MathE will have been widely spread in every participant country and disseminated across Europe through conferences, seminars and Erasmus mobility visits undergone by members. It is expected that such dynamics will have a direct interference in teaching and learning approaches and also in the motivation of all involved agents.

\section{CURRENT ACTIVITIES}

The MathE team is currently working on the conception of the visual identity and website (https://mathe.pixelonline.org/) of the project as well as on the compilation of the questions for the self assessment and teacher evaluation database.

The assesment questions of the library focus on a list of topics that are transversal to all higher education courses that offer a solid mathematical preparation.

Two types of assessments are being developed:

- Training assessments, where the students can do their self-evaluation for a given topic.

- Assessments that are proposed by teachers and can be used as the final assessment for a given course (maths, engineering or business among others).
Each Training Assessment will be produced randomly from the assessments database composed by questions/answers. In this way, the same student will be able to answer different training assessments about the same topic. The idea is to test if a certain topic that the student enrolled is already known and understood; if not or if the teachers believe that it needs to be deepened, after reviewing all the concepts, the student

Table 1. Topics covered in the MathE library

\begin{tabular}{|c|l|}
\hline \multirow{4}{*}{ Algebra } & $\begin{array}{l}\text { Eigenvalues and } \\
\text { eigenvectors }\end{array}$ \\
\cline { 2 - 2 } & Matrices and determinants \\
\cline { 2 - 2 } & Vector spaces \\
\cline { 2 - 2 } Calculus & Complex numbers \\
\hline \multirow{4}{*}{} & Functions of one variable \\
\cline { 2 - 2 } & $\begin{array}{l}\text { Functions of } \\
\text { variables }\end{array}$ \\
\cline { 2 - 2 } & Differentiation \\
\cline { 2 - 2 } & Simple integration \\
\cline { 2 - 2 } & Double integration \\
\hline \multirow{2}{*}{ Statistics } & \\
\hline \multirow{2}{*}{ Geometry } & Graph theory \\
\cline { 2 - 2 } & Number theory \\
\hline & Elementary geometry \\
\cline { 2 - 2 } & Geometry of the plane \\
\cline { 2 - 2 } & Geometry of the space \\
\hline
\end{tabular}

can answer another training assessment to measure its degree of confidence to perform a final assessment. The Assessments procedure will work in a similar way.

When students answer a Training Assessment, they will have immediate access to the obtained mark: the test will randomly select questions from a given set and after the student submits the test, the mark will automatically appear, enabling selfevaluation); when students answer an Assessment, the corresponding mark will appear for the student and also for the teacher - the Assessment will only be available in the classroom and when the teacher allows the assessment to happen.

It is expected that the MathE library will contribute to create and develop an educational culture driven by data analysis and self-evaluation (available at any time and in any place) that, in turn, will ensure effective interaction among stakeholders in education, establishing a learning environment that provides equal conditions for all students, offering all the same opportunities for learning and progressing.

The MathE library currently under construction will also provide a special section offering students and teachers learning resources - online exercises, online testing, videos, written notes or others - to reinforce specific mathematical topics covered by the questions. When a student fails an answer, he/her will be redirected to a resource that covers the topic. 
One of the most innovative features of MathE is the organization, by topics, of the subjects that partner universities feel the need to deepen; they will be freely available on the Internet and can be used by the partners and users outside the consortium. All such material will be previously validated by the consortium.

The MathE library is different from a common online course, since the material is permanently available online, in different languages - English is always mandatory in each item (spoken or in subtitles). Some items can be translated to national languages or spoken in national languages.

It should be mentioned that there is a great number of video lessons available on internet, but some of them have scientific errors and are not organized for the higher education population. The Online Math Library should facilitate the access to high-quality certified academic support.

During this period, the lecturers and researchers rely on the collaboration of a group of students of each partner institution that volunteered to test the questions and share their impressions and suggestions for improvement. The testing phase allows the collection of relevant feedbacks from the end users in order to further improve the deliverables produced and create results that are fully consistent with their needs and expectations.

\section{CONCLUSIONS}

It is well-known that, in order to achieve a competitive economy in the modern world, one must focus on three key factors: knowledge, innovation and entrepreneurship. In the context of the acquisition of knowledge, education is the key to increase competitiveness and welfare.

At a European level, the project will make a strong contribution to the modernization of Europe's higher education systems concerning the acquisition of mathematical competences.

The application of the gained outcomes on everyday teaching and learning activities has the potential to raise the quality of the teaching of Mathematics and mathematics related subjects in partner HEIs and effective dissemination will make the impact spread to other countries of the EU and to the rest of the world. A closer cooperation between partner organizations will result in increased cross-border cooperation, also in future co-operation projects. A greater number of young people is expected to become interested in deepening their knowledge in the scientific area of mathematics, perceive it as an attractive and important field to study and work in therefore making the expected number of well-succeeding STEM students increase in the EU in the long-term.

The example of MathE can be adapted by other kinds of education-related institutions (for example, secondary schools) to carry out similar databases for their students. The MathE consortium can be a helpful partner in the implementation of similar models in their schools.

\section{ACKNOWLEDGMENTS}

This work has been supported by COMPETE: POCI-010145-FEDER-007043 and FCT - Fundação para a Ciência e Tecnologia, Portugal, within the Project Scope: UID/CEC/00319/2013 and Erasmus+ Programme project n. 2018-1-PT01-KA203-047361.

\section{REFERENCES}

[1] T. Brahimi and A. Sarirete, "Learning outside the classroom through MOOCs", Computers in Human Behavior, vol. 51, pp. 604609, 2015.

[2] D. Cheng and M. Walters, "Peer-assisted learning in mathematics: an observational study of student success", Journal of Peer Learning, vol. 2, pp. 23-39, 2009.

[3] European Commission, "European Commission launches network to foster web talent through Massive Open Online Courses (MOOCs)", Press Realease, 2014.

[4] G. W. Henning, "Tenet two: cultivating a culture of assessment", In K. Yousey-Elsener, E. M. Bentrim, \& G. W. Henning (Eds.), Coordinating student affairs divisional assessment, pp. 11-34, 2015. [5] K. Hew and W. S. Cheung, 'Students' and instructors' use of massive open online courses (MOOCs): Motivations and challenges", Educational Research Review, vol. 12, pp. 45-58, 2014.

[6] K. Hone and G. El Said, "Exploring the factors affecting MOOC retention: A survey study", Computers \& Education, vol. 98, pp. 157-168, 2016.

[7] D. W. Johnson and R. T. Johnson, "Using technology to revolutionize cooperative learning: an opinion", Frontiers in Psychology, 2014.

[8] A. Littlejohn, N. Hood, C. Milligan and P. Mustain, "Learning in MOOCs: motivations and self-regulated learning in MOOCs", Internet and Higher Education, vol. 29, pp. 40-48, 2016.

[9] J. Navarra-Madsen and P. Ingram, "Mathematics tutoring and student success", Procedia Social and Behavioral Science, vol. 8, pp. 207-212, 2010.

[10] B. Schmitz, R. Klemke, and M. Specht, "Effects of mobile gaming patterns on learning outcomes: a literature review". Int. J. Technol. Enhanc. Learn. 4, 5/6, pp. 345-358, 2012.

[11] B. Schmitz, R. Klemke, and M. Specht, "The impact of coupled games on the learning experience of learners at-risk". Pervasive Mob. Comput. 14, C, pp. 57-65, 2014.

[12] H. B. Shapiro, Clara H. Lee, Noelle E. Nyman Roth, Kun Li, Mine Çetinkaya-Rundel and Dorian A. Canelas , "Understanding the massive open openline course (MOOC) student experience: an examination of attitudes, motivations and purposes", Computers \& Education, vol. 110, pp. 35-50, 2017.

[13] M. Specht, M. and R. Klemke, "Enhancing learning with technology", In D. Milosevic (Ed.), Proceedings of the fourth international conference on eLearning (eLearning 2013), pp. 37 45, 2013.

[14] S. S. Vestal, T. Brandenburger and A. Furth, "Improving student success in Calculus I using a co-requisite Calculus I Lab", PRIMUS, vol. 25:4, pp. 381-387, 2015.

[15] J. Waldock, P. Rowlett, C. Cornock, M. Robinson and H. Bartholomew, "The role of informal learning spaces in enhancing student engagement with mathematical sciences", International 
Journal of Mathematical Education in Science and Technology, vol. 48:4, pp. 587-602, December 2016.

\begin{tabular}{|c|c|c|}
\hline $\begin{array}{c}\text { Maria F. } \\
\text { Pacheco }\end{array}$ & $\begin{array}{c}\text { Associate } \\
\text { professor }\end{array}$ & $\begin{array}{c}\text { Combinatorial } \\
\text { optimization, graph theory, } \\
\text { innovative tools in } \\
\text { teaching, mathematical } \\
\text { education }\end{array}$ \\
\hline Ana Pereira & Full professor & $\begin{array}{c}\text { Robotics, optimization, } \\
\text { innovative tools in } \\
\text { teaching, mathematical } \\
\text { education }\end{array}$ \\
\hline Florbela & $\begin{array}{l}\text { Associate } \\
\text { professor }\end{array}$ & $\begin{array}{c}\text { Nonlinear and nonconvex } \\
\text { optimization, innovative } \\
\text { tools in teaching, } \\
\text { mathematical education }\end{array}$ \\
\hline
\end{tabular}

